\begin{tabular}{|c|c|c|c|c|c|c|c|}
\hline \multirow{2}{*}{ 燒 塊 } & \multicolumn{2}{|c|}{ 粉末度(殘滞\%) } & \multirow{2}{*}{$\begin{array}{c}\text { 水量 } \\
\text { (\%) }\end{array}$} & \multicolumn{4}{|c|}{ 小型附厓力 $\left(\mathrm{kg} / \mathrm{cm}^{2}\right)$} \\
\hline & $4900 孔 / \mathrm{cm}^{2}$ & $1000 孔 / \mathrm{cm}^{2}$ & & 3日 & 7日 & 28 日 & オートクレープ \\
\hline No.1 $(3 \% \mathrm{MgO})$ & 1.5 & 12.6 & 5.3 & 53 & 126 & 200 & 213 \\
\hline No.2(5\% MgO) & 1.6 & 13.0 & 51 & 62 & 127 & 192 & 233 \\
\hline No $3(8 \% \mathrm{MgO})$ & 1.4 & 14.3 & 54 & 47 & 110 & 170 & 177 \\
\hline
\end{tabular}

上表に據ればマグネシアが $3 \%$ の時と $5 \%$ の時との間には大差なく, 寧ろ $5 \%$ の方が優れてるるやろであ る。マグネシア $8 \%$ のセメントは幾分弱いが他に缺點なく實用上には差索がない。

要するにマグネシアは 5\%位含まれてるても無害で寧ろ有利なやうに思はれる。

\title{
2 要旨
}

1 著者は㩆にポルトランドセメントのマグネシアは約 8\%まで無害であると報告した（本誌，40，[480]，76 9, 昭 7)。更に之を確めんが䳕に總て工業原料を用る,水硬率を 2.15 に，珪酸率を 2.70 に，鐵率を 1.50 に一

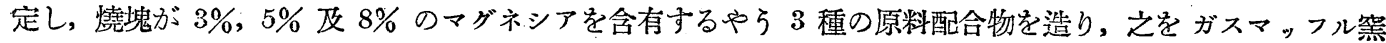
で燒成し，石膏を加へて粉末し，得たるセメントの小型耐壓力を測定した。

2 材路 3 28 日に於てはマグネシア含有量 $3 \%$ と 5\%の間には殆ど强度の差を見なかつた。マグネシア $8 \%$ のセメントは著しく弱かつたが; 他の缺點を認めなかつた。

3 供試體をオートクレブに大れ $1400^{\circ} \mathrm{C}$ で 6 時間熱した後の强度は，マグネシア $5 \%$ のセメントは $3 \%$ セ メントに比して著しく優り，8\%のセメントは著しく劣つてるたが他の缺點を示さなかつた。

4 要するにマグネシアは $5 \%$ 位までは無害で寧ろ有利なやうである。

本研究は文部省自然科學研究獎萿補助費に依つた。倘著者は化學分析を擔任せられた棚橋壽一氏に對して梁 く感謝する次第である。(東京工業大學誉業學科砫究室)（昭和 10 年 4 月 11 日受理）

\section{ソーダライムマグネシア硝子の耐水性に就て}

\author{
田端耕造 - 橫山辰雄 - 小林保 \\ Durability of Soda-lime-magnesia Glass. \\ By Közo Tabata, Tatsuo Yokoyama, and Tamotsu Kobayashi \\ Abstract
}

Durability in water of the glass $\mathrm{Na}_{2} \mathrm{O}(1-x) \mathrm{CaO}, x \mathrm{MgO}, y \mathrm{Al}_{2} \mathrm{O}_{3} 5.3 \mathrm{SiO}_{2}$, in which $x=0 \sim 1.0$ and $y=0 \sim 0.2$, was determined by the powder method at $95^{\circ} \mathrm{C}$ (by water bath) and at $170^{\circ} \mathrm{C}$ (by autoclave)

When $y$ was constant the durability decreased with the increase of $x$, but the amount of decrease was not so much and became smaller and smaller with the increase of $y$ and at last it became almost insignificant. When $x$ was constant the durability increased with the increase of $y$

The glass which had greater durability a $95^{\circ} \mathrm{C}$ had also greater durability at $170^{\circ} \mathrm{C}$.

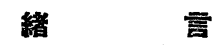

$\mathrm{Na}_{2} \mathrm{O}-\mathrm{CaO}-\mathrm{MgO}-\mathrm{SiO}_{2}$ 硝子の石灰をマグネシアで置換した場合及びアルミナを加へた場合其の 耐水性に如 何なる變化を生ずるかを粉未法で測定した。其の結果を此處に報告する。 


\section{1. 試洣}

$\mathrm{Na}_{2} \mathrm{O} \underset{x}{\stackrel{(1-x)}{\mathrm{MgO}} \mathrm{\textrm {CaO }}} y \mathrm{Al}_{2} \mathrm{O}_{3} 5.3 \mathrm{SiO}_{2} ;$ 但 $x=0,0.1,0.2,0.3,0.4,0.5,0.6,0.7,0.8,0.9,1.0 ; y=0,0.05,0.1,0.15$,

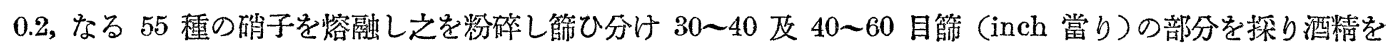
以て洗策して微枌を除き乾燥して貯へた。原料には化學藥品を用ひ硝子の分析は行はながつた。

\section{2 比}

\section{需}

粉末法に依る耐水性の決定に於ては結果の表示は一定容量の試料硝子に濰して瓷すを妥當とする。其の䉆に は試粼の比重を知るを要する。

本拭料の比重測定の結果は第1表の如くであつた。

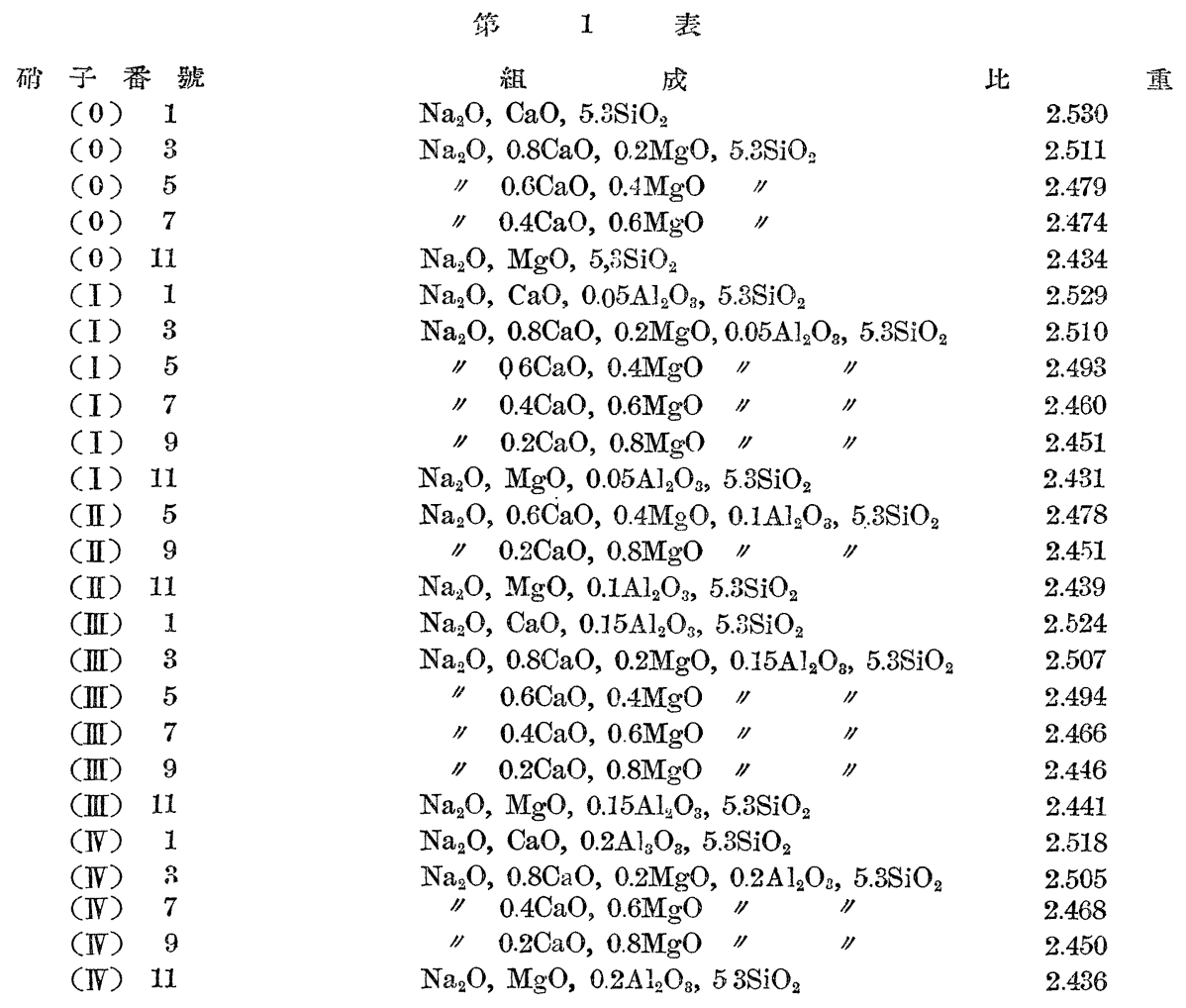

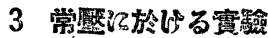

Silicox 印硬質硝子製 $200 \mathrm{cc}$ の三角フラスコに試料（40〜60 目節）を $10 \mathrm{~g}$ 秤取し蒸溜水 $100 \mathrm{cc}$ を加へ逆流

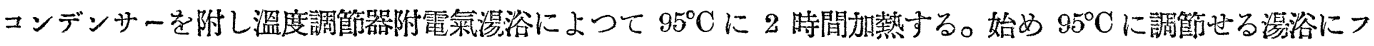
ラスコを涱すと $92^{\circ} \mathrm{C}$ に溫度が降るが約 15 分にして $95^{\circ} \mathrm{C}$ に戾る。時間はフラスコを浸した時を起點として 算へる。 2 時間後フラスコを取出し流水で冷却しメチールレッドを指示藥として $1 / 50 \mathrm{~N} . \mathrm{HCl}$ で滴定导る。 同時に蒸溜水のみを大れたるフラスコに同一處理を施しブランクテストを行ひ補正をなす。ブランクラストは 每问行つた。滴定の際は弱酸性, 中性, 弱アルカリ性の 3 種の液を用意し各々に指示藥を加へ之と比較しつつ 滴定を行ひ終點を定めた。此の結果は第 2 表及第 1 圖の如くである。但, $\mathrm{HCl}$ の $\mathrm{cc}$ 數は容積にして $4 \mathrm{~cm}^{3}$ の, 


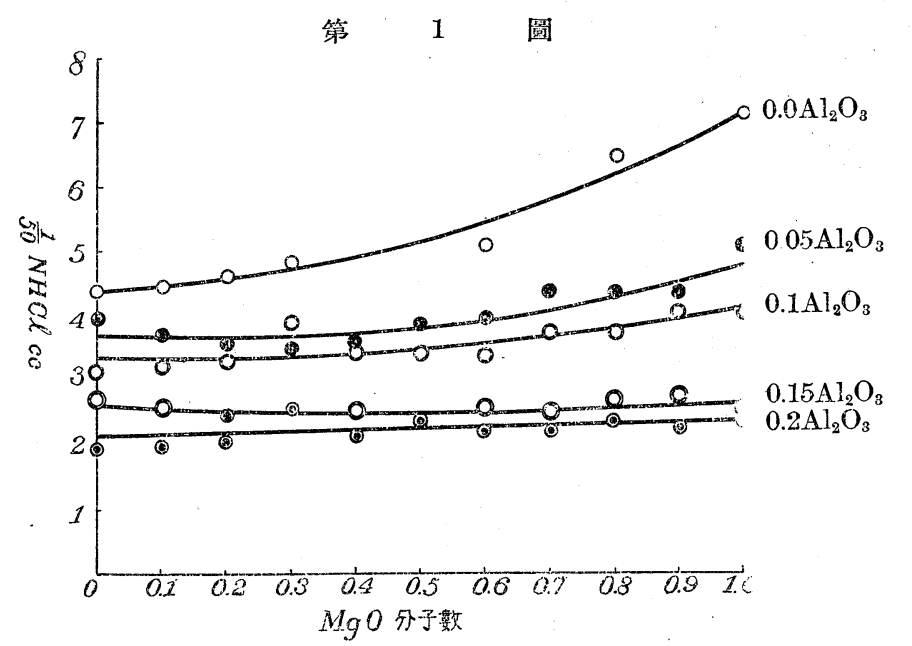

硝子に對する數である。此の數は 次の式に依り算出する。

$$
x=a \times \frac{d}{2.5}
$$

但， $a$ は $10 \mathrm{~g}$ の捎子に對して要し た $1 / 50 \mathrm{~N}, \mathrm{HCl}$ の cc 數, $d$ は該 确子の比重， $x$ は求むる數郎ち 4 $\mathrm{cm}^{3}$ の硝子に對して要する $\mathrm{HCl}$ の cc 數である。筒比重を實測し なかつたものは實測值より比例に 依り計算した值を用ひた。

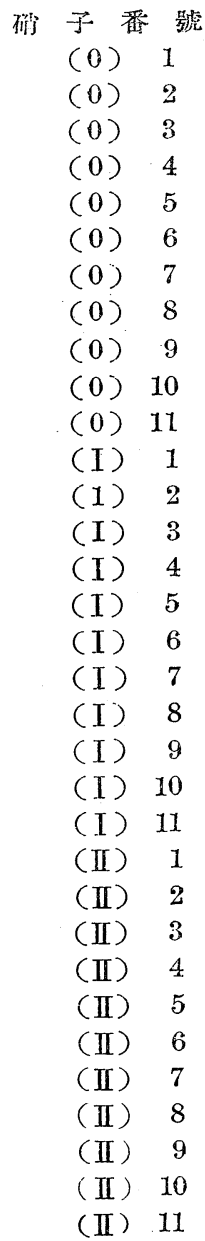

\section{笘 2 表}

艋

$\mathrm{Na}_{2} \mathrm{O}, \mathrm{CaO}, 5.3 \mathrm{SiO}_{2}$

$\mathrm{Na}_{2} \mathrm{O}, 09 \mathrm{CaO}, 0.1 \mathrm{MgO}, 53 \mathrm{SiO}_{2}$

" $0.8 \mathrm{CaO}, 0.2 \mathrm{MgO}$ "

" $0.7 \mathrm{CaO}, 0.3 \mathrm{MgO}$ "

" $0.6 \mathrm{CaO}, 0.4 \mathrm{MgO}$ "

" $0.5 \mathrm{CaO}, 0.5 \mathrm{MgO}$ "

" $0.4 \mathrm{CaO}, 0.6 \mathrm{MgO}$ "

" $0.3 \mathrm{CaO}, 0.7 \mathrm{MgO}$ "

" $0.2 \mathrm{CaO}, 0.8 \mathrm{MgO}$ "

". $0.1 \mathrm{CaO}, 0.9 \mathrm{MgO}$ "

$\mathrm{Na}_{2} \mathrm{O}, \mathrm{MgO}, 5.3 \mathrm{SiO}_{2}$

$\mathrm{Na}_{2} \mathrm{O}, \mathrm{CaO}, 0.05 \mathrm{Al}_{2} \mathrm{O}_{3}, 5.3 \mathrm{SiO}_{2}$

$\mathrm{Na}_{2} \mathrm{O}, 0.9 \mathrm{CaO}, 0.1 \mathrm{MgO}, 0.05 \mathrm{Al}_{2} \mathrm{O}_{3}, 5.3 \mathrm{SiO}_{2}$

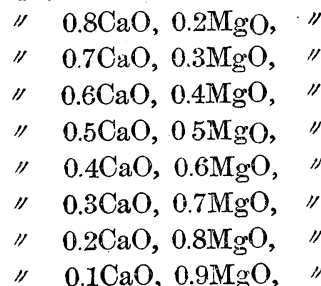

$\mathrm{Na}_{2} \mathrm{O}, \mathrm{MgO}, 0.05 \mathrm{Al}_{2} \mathrm{O}_{\varepsilon}, 5.3 \mathrm{SiO}_{2}$

$\mathrm{Na}_{2} \mathrm{O}, \mathrm{CaO}, 0.1 \mathrm{Al}_{2} \mathrm{O}_{3}, 5.3 \mathrm{SiO}_{2}$

$\mathrm{Na}_{2} \mathrm{O}, 0.9 \mathrm{CaO}, 0.1 \mathrm{MgO}, 0.1 \mathrm{Al}_{2} \mathrm{O}_{3}, 5.3 \mathrm{SiO}_{2}$

" $0.8 \mathrm{CaO}, 0.2 \mathrm{M}_{3} \mathrm{O}$ "

" $0.7 \mathrm{CaO}, 0.3 \mathrm{MgO}$ "

" $0.6 \mathrm{CaO}, 0.4 \mathrm{MgO} / "$

" $0.5 \mathrm{CaO}, 0.5 \mathrm{MgO}$ "

" $0.4 \mathrm{CaO}, 0.6 \mathrm{MgO}$ "

3.37

" $0.3 \mathrm{CaO}, 0.7 \mathrm{MgO}$ " " $\quad 3.74$

" $0.2 \mathrm{CaO}, 0.8 \mathrm{MgC} "$ " 3.74

" $0.1 \mathrm{CaO}, 0.9 \mathrm{MgO} "$ " " 4.02

$\mathrm{Na}_{2} \mathrm{O}, \mathrm{MgO}, 0.1 \mathrm{Al}_{2} \mathrm{O}_{3}, 5.3 \mathrm{SiO}_{2}$
$1 / 50 N . \mathrm{HCl}$ cc 数.

4.37
4.45
4.61
4.82
-
-
5.07
-
6.48
-
7.11
3.96
3.76
3.54
3.50
3.61
3.88
3.95
4.35
4.39
4.33
5.11
3.12
3.21
3.30
3.90
3.40
3.38
3.37
3.74
3.74
4.02
4.02




$\begin{array}{cc}\text { 子 确 } & \text { 號 } \\ \text { (III) } & 1 \\ \text { (III) } & 2 \\ \text { (III) } & 3 \\ \text { (III) } & 4 \\ \text { (III) } & 5 \\ \text { (III) } & 6 \\ \text { (III) } & 7 \\ \text { (III) } & 8 \\ \text { (III) } & 9 \\ \text { (III) } & 10 \\ \text { (III) } & 11 \\ \text { (IV) } & 1 \\ \text { (IV) } & 2 \\ \text { (IV) } & 3 \\ \text { (IV) } & 4 \\ \text { (IV) } & 5 \\ \text { (IV) } & 6 \\ \text { (IV) } & 7 \\ \text { (IV) } & 8 \\ \text { (IV) } & 9 \\ \text { (IV) } & 10 \\ \text { (IV) } & 11 \\ \text { (1) } & \end{array}$

\begin{tabular}{|c|c|c|c|c|}
\hline \multicolumn{4}{|c|}{ 組 $\quad$ 成 } & $1 / 50 \mathrm{~N} . \mathrm{HCl}$ cc 數 \\
\hline \multirow{2}{*}{\multicolumn{4}{|c|}{$\begin{array}{l}\mathrm{Na}_{2} \mathrm{O}, \mathrm{CaO}, 0.15 \mathrm{Al}_{2} \mathrm{O}_{3}, 5.3 \mathrm{SiO}_{2} \\
\mathrm{Na}_{2} \mathrm{O}, 0.9 \mathrm{CaO}, 0.1 \mathrm{MgO}, 0.15 \mathrm{Al}_{2} \mathrm{O}_{3}, 5.3 \mathrm{SiO}_{2}\end{array}$}} & 2.70 \\
\hline & & & & 2.57 \\
\hline " & $0.8 \mathrm{CaO}, 0.2 \mathrm{MgO}$ & " & "/ & 2.44 \\
\hline " & $0.7 \mathrm{CaO}, 0.3 \mathrm{MgO}$ & " & "I & 2.54 \\
\hline " & $0.6 \mathrm{CaO}, 0.4 \mathrm{MgO}$ & " & $"$ & 2.51 \\
\hline " & $0.5 \mathrm{CaO}, 0.5 \mathrm{MgO}$ & " & " & 2.38 \\
\hline " & $0.4 \mathrm{CaO}, 0.6 \mathrm{MgO}$ & "I & "I & 2.58 \\
\hline " & $0.3 \mathrm{CaO}, 0.7 \mathrm{MgO}$ & " & " & 2.18 \\
\hline " & $0.2 \mathrm{CaO}, 0.8 \mathrm{MgO}$ & " & " & 2.66 \\
\hline " & $0.1 \mathrm{CaO}, 0.9 \mathrm{MgO}$ & " & "1 & 2.77 \\
\hline \multicolumn{4}{|c|}{$\mathrm{Na}_{2} \mathrm{O}, \mathrm{MgO}, 0.15 \mathrm{Al}_{2} \mathrm{O}_{3}, 5.3 \mathrm{SiO}_{2}$} & 2.36 \\
\hline \multirow{3}{*}{\multicolumn{4}{|c|}{$\begin{array}{l}\mathrm{Na}_{2} \mathrm{O}, \mathrm{CaO}, 0.2 \mathrm{Al}_{2} \mathrm{O}_{3}, 5.3 \mathrm{SiO}_{2} \\
\mathrm{Na}_{2} \mathrm{O}, 0.9 \mathrm{CaO}, 0.1 \mathrm{MgO}, 0.2 \mathrm{Al}_{2} \mathrm{O}_{3}, 5.3 \mathrm{SiO}_{2} \\
\quad / / 0.8 \mathrm{CaO}, 0.2 \mathrm{MgO}\end{array}$}} & 1.92 \\
\hline & & & & 1.95 \\
\hline & & & & 2.01 \\
\hline " & $0.7 \mathrm{CaO}, 0.3 \mathrm{MgO}$ & " & " & 2.63 \\
\hline " & $0.6 \mathrm{CaO}, 0.4 \mathrm{MgO}$ & " & " & 2.12 \\
\hline " & $0.5 \mathrm{CaO}, 0.5 \mathrm{MgO}$ & /" & " & 2.37 \\
\hline "l & $0.4 \mathrm{CaO}, 0.6 \mathrm{MgO}$ & "I & " & 2.18 \\
\hline " & $0.3 \mathrm{CaO}, 0.7 \mathrm{MgO}$ & " & " & 2.46 \\
\hline " & $0.2 \mathrm{CaO}, 0.8 \mathrm{MgO}$ & " & " & 2.33 \\
\hline " & $0.1 \mathrm{CaO}, 0.9 \mathrm{MgO}$ & "I & " & 2.24 \\
\hline \multicolumn{4}{|c|}{$\mathrm{Na}_{2} \mathrm{O}, \mathrm{MgO}, 0.2 \mathrm{Al}_{2} \mathrm{O}_{3}, 5.3 \mathrm{SiO}_{2}$} & 2.56 \\
\hline
\end{tabular}

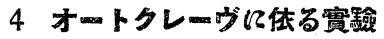

オートクレーヴに蒸溜水 $500 \mathrm{cc}$ を入れ此の上方に試料粒 (30 40 目穊) $5 \mathrm{~g}$ 及蒸溜水 $17 \mathrm{cc}$ を入れて蓋をな

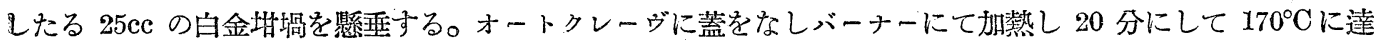
せしめる。然る後 2 時間加熱を續けて $170^{\circ} \mathrm{C}$ に保ちたる後加熱を止め放冷すること 1 時間にしてオートクレ

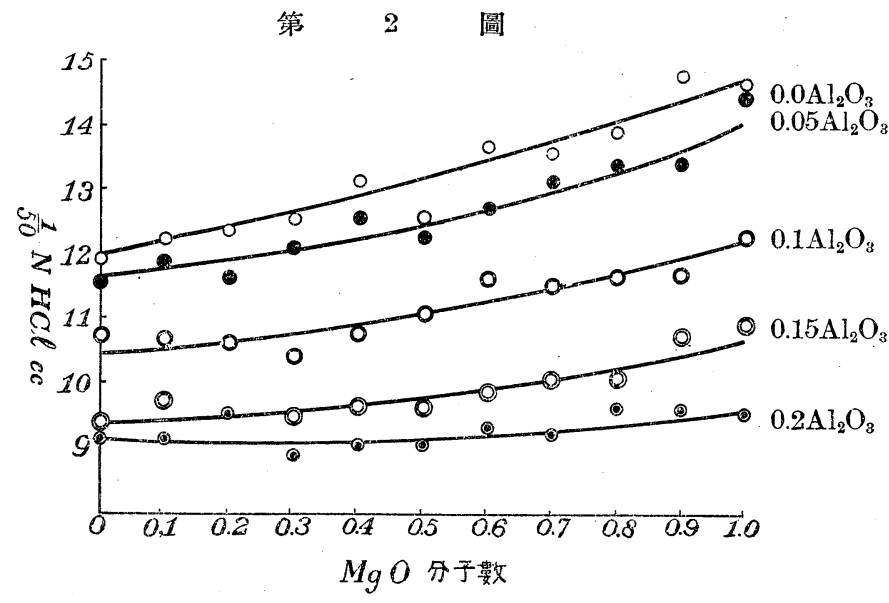

ーヴの蓋を開き坩堝を取出し內 容を $100 \mathrm{cc}$ の蒸溜水にてビーカ ーに移しメチルレッドを指示藥 として滴定した。

此の結果は第 3 表交第 2 圖 の如くである。而して今硝子粒 を球形と假定し且其の直俓が 2 個の節の目の大きさの本均値に 等しいと假定して計算すればオ ートクレーヴの際は常厣の際に 較べて 4〜7 倍位溶けた事にな る。(必しも球形とする必要は無

く或る任意の形に相似であると假定すればよい譯であらうが便宜上上の如くした)。 


$\begin{array}{ccc} & & \\ \text { 子第 } \\ \text { (0) } & 1 & \text { 番 } \\ \text { (0) } & 2 & 11.91 \\ \text { (0) } & 3 & 12.25 \\ \text { (0) } & 4 & 12.37 \\ \text { (0) } & 5 & 12.56 \\ \text { (0) } & 6 & 13.19 \\ \text { (0) } & 7 & 12.60 \\ \text { (0) } & 8 & 13.70 \\ \text { (0) } & 9 & 13.60 \\ \text { (0) } & 10 & 13.93 \\ \text { (0) } & 11 & 14.80 \\ \text { (I) } & 1 & 14.70 \\ \text { (I) } & 2 & 11.57 \\ \text { (I) } & 3 & 11.90 \\ \text { (I) } & 4 & 11.66 \\ \text { (I) } & 5 & 12.11 \\ \text { (I) } & 6 & 12.60 \\ \text { (I) } & 7 & 12.29 \\ \text { (I) } & 8 & 12.75 \\ \text { (I) } & 9 & 13.20 \\ \text { (I) } & 10 & 1347 \\ \text { (I) } & 11 & 13.45 \\ \text { (II) } & 1 & 14.50 \\ \text { (II) } & 2 & 10.79 \\ \text { (II) } & 3 & 10.70 \\ \text { (II) } & 4 & 10.63 \\ \text { (II) } & 5 & 10.42 \\ \text { (1) } & 10.78\end{array}$

表

砂子番號 $1 / 50 \mathrm{~N}$. HClce 數

(II) $6 \quad 11.10$

(III) $7 \quad 11.66$

(III) $8 \quad 11.53$

(III) $9 \quad 11.69$

(II) $10 \quad 11.70$

(II) $11 \quad 12.31$

(III) $1 \quad 9.41$

(III) $2 \quad 9.75$

(III) $3 \quad 9.50$

(III) $4 \quad 9.50$

(III) $5 \quad 9.69$

(III) $6 \quad 9.65$

(III) $7 \quad 9.90$

(III) $8 \quad 10.09$

(III) $9 \quad 10.12$

(III) $10 \quad 10.78$

(III) $11 \quad 10.95$

(IV) $1 \quad 9.15$

(IV) $2 \quad 9.14$

(IV) $3 \quad 9.53$

(IV) $4 \quad 8.90$

(IV) $5 \quad 9.09$

(IV) $6 \quad 9.04$

(IV) $7 \quad 9.33$

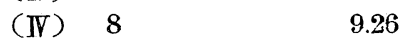

(IV) $\quad \begin{array}{ll}8 & 9.63\end{array}$

(IV) $10 \quad 9.62$

(IV) $.11 \quad 9.57$

\section{5 結語}

以上の實驗結果より見るに $\mathrm{Na}_{2} \mathrm{O}_{x}^{(1-x) \mathrm{CaO}} \mathrm{MgO}^{2} \mathrm{Al}_{2} \mathrm{O}_{3} 5.3 \mathrm{SiO}_{2}$ 但し $x=0 \sim 1.0, y=0 \sim 0.2$ に於て $y$ が一定なら ば $x$ の增加と共に耐水性は減少する, 併し其の減少の程度は左程大で無く且 $y$ を霄すにつれて次第に小とな り終に殆ど認め難くなる。 $x$ が一定ならば $y$ を督せば耐水性が增す。此の組成と耐水性との關係は $95^{\circ} \mathrm{C} の$ 實驗に於ても $170^{\circ} \mathrm{C}$ (オートクレーヴに依る)の實驗に於ても同樣で岁つた。

終りに臨み本研究は故ドゥトルワグネル記念獎學資金に体て行はれたものである事を記し感謝の意を表す る。(昭和 10 年 7 月 2 日受理) 